\title{
Guest Editors’ Preface
}

In November 2014 an international conference was held in Debrecen, Hungary which was organised by the University of Debrecen Law School and the Hungarian Academy of Sciences Centre for Social Sciences, Institute for Legal Studies. The conference served as a first step for carrying out a new research project entitled 'How to Measure the Quality of Judicial Reasoning'.

The idea behind the research project is that while in the past two decades various 'external' (public trust, satisfaction, affordability, accessibility, etc.) and 'internal' or 'formal' (timeliness, fairness of judicial process, independence and accountability of courts) benchmarks have been worked out for the assessment of the quality of judicial activity, the question remains whether we can measure the quality of the actual judicial reasoning at all.

This question is important on the one hand from a purely academic point of view: if there are methods to measure it, then traditional depictions of judicial activity as some kind of art (ars boni et aequi) or the manifestation of the mystical 'judicial wisdom' becomes unconvincing. If we can measure the quality of legal argumentation then we will be able to evaluate decisions of the judiciary and hold its members accountable in case their reasoning is considered unsatisfactory, in the same way as the work of other professions is also held up to scrutiny. A convincing methodology to measure the quality of judicial reasoning could possibly shift our paradigm of how we think about law in general.

Besides the academic interest, the issue is relevant also from a very practical point of view: the objective measurement of the quality of work is spread not only throughout academia but it also seems unstoppable within the judiciary. The usual crude methods (e.g., number of judgments, hours of sitting, number of reversed cases on appeal) do not seem, however, to be able to reflect convincingly the real quality of a judge's work.

The researchers are interested in both the academic literature and the practice of judicial organisations in several European countries, i.e., among others, in questions such as: What is expected from judicial reasoning? Is there a general concept of good quality with regard to judicial reasoning? Is it spelled out in any legal documents (statutes, internal judicial guidelines, appellate cases)? If not, then how are these requirements enforced? Are there any attempts to measure the quality of judicial reasoning? If yes, then is it rather a peer review method, a numerical measurement, or a mixture of these?

On the first day of the conference distinguished invited speakers from various European countries spoke about the theoretical problems of quality assessment in the field of judicial activity (Zenon Bankowski, Arthur Dyevre) and the practical developments of judicial 'quality assurance' in some major European jurisdictions (Markku Kiikeri, Francesco Contini, Gar Yein Ng, Norman Weiß, Zdenek Kühn). At the end of the first day a roundtable discussion took place about the general methodological problems of measuring the quality of judicial activity (Philip Langbroek, Zoltán Fleck, Nicolaas Bel, Mariusz J. Golecki).

The second day was open for scholars and legal practitioners who had any contribution to make to this research topic from their own perspective. Case studies and theoretical explanations of these issues (in different contexts, such as theory of adjudication, 'virtue jurisprudence', legal sociology and political philosophy) were equally welcome. 
In the current issue of Acta Juridica Hungarica we selected to publish some papers presented on the second day of the conference which represent different approaches to this very wide research topic.

The first author is Mihály Maczonkai, who distinguished between two models of judicial reasoning: a 'syllogistic' one based on deduction and a 'heuristic' one that uses prudential wisdom. He argues that the latter one is the better description of judges' work. Therefore one cannot find a precise professional protocol for the assessment of the quality of judicial reasoning.

Nonetheless, almost every other paper emphasizes the importance of well-reasoned judicial decisions and why the lack of proper justification is a problem. Zsolt Zödi's concludes that the highly formalistic way in which Hungarian judgements often cite previous judicial decisions does not add any value to the quality of judicial reasoning.

Eszter Kirs comes to a similar conclusion when she highlights the problems of judicial interpretation and reasoning in a single international court (ICTY) decision. The conclusion of Kirs's case-study is that it can be a problem if judges decide serious moral and political issues of international law without a deep analysis of the norms of customary international law and the relevant precedents of case law.

One of the essential parts of legal argumentation is the interpretation of the text of the law. That is why the method of interpreting the law has a determinative impact on the quality of legal justification. Ievgen Zvieriev exposes and criticises the interpretative method of Ukrainian courts which, as a result of the socialist heritage, insist on the textualist approach. This practice sometimes leads to sheer absurdity.

In relation to judicial quality, it can also be a problem if domestic courts ignore the relevant international legal norms. This worrying attitude is present in the jurisprudence of Indonesian courts - as we learnt from the case-study written by Dodik Setiawan Nur Heriyanto.

The sentencing practice in criminal cases is a peculiar part of the quality assessment. In this case the judge is not bound to the (legislated) laws and precedents in the same way as they are in legal interpretation. That is why it requires serious effort to find the proper standards of reasoning when it comes to justification of the delivered punishment. In his paper, Huang Gui throws light on the external and internal factors that can have an influence on judges when they determine the punishment of criminal offenders. Analysing the Chinese judicial practice, he demonstrates that without having clear norms which determine the proper types and measures of punishments judges are affected by many extralegal factors which can lead to a highly unjust sentencing practice.

The reasoning of constitutional courts also has its special characteristics. This raises the question: what are the special methods for evaluating the quality of judgements made in politically sensitive cases. Zoltán Pozsár-Szentmiklósy, Kálmán Pócza and András Molnár try to shed light on the requirements of good quality constitutional adjudication.

Pozsár-Szentmiklósy seeks to highlight numerous benefits of the principle of proportionality, which serves as a global argumentative framework in human rights adjudication. He argues that proportionality analysis provides an adequate scheme for carrying out transparent and verifiable reasoning, and it is also apt to mitigate fundamental legitimacy problems constitutional courts must often face due to their growing influence in political decision-making. For him, proportionality is the proper method for the courts to tackle constitutional issues, and by providing a formalized structure for the thought process it helps to assess the quality of constitutional reasoning. 
Pócza reveals how the role of constitutional courts and the legitimacy of their decisions can vary according to background democratic theories. He suggests that the quality of constitutional reasoning might increase if courts indicate at least implicitly their role perception in terms of normative theories of constitutional democracy since these normative reflections can explain different judicial approaches and attitudes in the course of constitutional review.

In his paper Molnár makes some important clarifications concerning the appropriate use of the concept of judicial activism and proposes a new approach to judicial activism on the basis of how courts use scientific considerations external to law in their reasoning. At the end of his paper he comes to the conclusion that in terms of this new approach the US Supreme Court in the first decades of the twentieth century can be considered as a passivist rather than an activist court.

To sum up, we can say that it is a worthwhile challenge to search for the criteria of correct judicial reasoning. The issue of the quality of justification can be relatively separated from the problem of correctness of the decision; proper justification may have a certain value in itself. Nonetheless, effective research requires analyzing this very complex issue from various perspectives.

We are grateful to all participants of the conference for the lively and deep debates, which gave us many insights into how to develop our research project. The guest editors are indebted to András Jakab, the director of the Institute for Legal Studies for his support and advice as well as to the Editor-in-Chief of Acta Juridica Hungarica, Professor Éva Jakab, who provided the opportunity to edit this special issue of the journal. We could not have coped with the technical issues of the editorial work without the effective assistance of Gergely Deli. Finally, we thank Zsófia Zsoldics (PhD student at the University of Debrecen) for her help in processing the submitted papers.

Mátyás Bencze

Ágnes Kovács

Krisztina Ficsor 